\title{
A bibliometric analysis of global forest ecology research during 2002-2011
}

\author{
Yajun Song ${ }^{1,2}$ and Tianzhong Zhao ${ }^{1 *}$
}

\begin{abstract}
Bibliometric is increasingly used for the analysis of discipline dynamics and management related decision-making. This study analyzes 937,923 keywords from 78,986 articles concerning forest ecology and conducts a serial analysis of these articles' characteristics. The articles' records, published between 2002 and 2011, were downloaded from the Web of Science, and their keywords were exported by Java processing programs. The result shows that forest ecology studies focused on forest diversity, conservation, dynamics and vegetation in the last decade. Developed countries, such as the USA, Canada, and Germany, were the most productive countries in the field of forest ecology research. From 2002 to 2011, the number of articles published annually related to forest ecology grew at a stable rate, as indicated by the fit produced by a high determination coefficient $\left(R^{2}=0.9955\right)$. The findings of this study may be applicable for planning and managing forest ecology research and partners involved in such research may use this study as a reference.
\end{abstract}

Keywords: Article analysis, Bibliometric, Forest ecology, Java, Keyword frequency analysis

\section{Introduction}

Bibliometric analysis is an important part of reference and research services. Forest ecology is closely related to forest management and many studies have been performed from various perspectives, including studies of ecosystems at multiple forest spatial scales (Rodrigues et al. 2011; Sitzia et al. 2010), long term ecosystem change (Diaz et al. 2007; van Oudenhoven et al. 2012), climate change (Cheaib et al. 2012; Şekercioğlu et al. 2012), soils (McLachlan and Bazely 2003; Wang et al. 2011), physiography (Morrissey et al. 2009; Rubio and Escudero 2005), carbon balance (Mitchell et al. 2009; Sillett et al. 2010), nutrient cycling (Berger et al. 2009; XU and Chen 2006), landscape ecology (Loucks et al. 2001; Wintle et al. 2005) and biodiversity (Hanberry et al. 2012; Lamb et al. 2005). In addition to these studies, a bibliometric analysis of global forest ecology could provide a fresh look at the current status of global forest ecology research and help identify hot spots.

In recent years, along with its continuously expanding range of application, bibliometric analysis plays an increasingly important role in management and decision-

\footnotetext{
* Correspondence: ztz@bjfu.edu.cn

${ }^{1}$ School of Information Science \& Technology, Beijing Forestry University, No.35 Tsinghua East Road, Beijing, Haidian District 100083, P.R. China Full list of author information is available at the end of the article
}

making in science and technology. It has been used to document the development of some research fields (Grandjean et al. 2011; Hendrix 2008; Narotsky et al. 2012; van Eck et al. 2010; van Raan 2006), including forestry (Dobbertin and Nobis 2010; Perez et al. 2004).

In this study, we perform a bibliometric analysis of forest ecology research over the last 10 years (2002-2011) aimed at (1) examining the temporal hot topics of forest ecology research by keyword frequency analysis, (2) revealing the distribution of articles by country/region, organization, funding agency, research area, author, year and publication name for articles covering forest ecology research and revealing advancements in forest ecological research, and (3) providing a new keywords frequency analysis method, which may benefit future research.

\section{Materials and methodology \\ Data collection}

Literature records, our analytical objects, were derived from the Web of Science, an online academic citation index database provided by Thomson Reuters. To define search terms, we used the "thesaurus" tool of Commonwealth Agricultural Bureaux (CAB) Abstracts.

We conducted a search on the word "ecology" in CAB Abstracts and the search produced 41 terms, including 19 narrower terms and 22 other related terms (Figure 1). 


\begin{tabular}{|c|c|c|c|c|}
\hline \multicolumn{3}{|c|}{$\checkmark$ ecology } & Hits & 39976 \\
\hline & \multicolumn{4}{|c|}{ [Used For] } \\
\hline \multicolumn{5}{|c|}{ ecologia } \\
\hline & \multicolumn{4}{|c|}{ [Narrower Terms] } \\
\hline & 回 & animal ecology & & 6052 \\
\hline & 回 & autecology & & 1150 \\
\hline & 四 & chemical ecology & & 733 \\
\hline & 四 & community ecology & & 3503 \\
\hline & 四 & dendroecology & & 213 \\
\hline & 四 & fire ecology & & 1529 \\
\hline & 四 & forest ecology & & 9340 \\
\hline & $\square$ & freshwater ecology & & 2471 \\
\hline & $\square$ & human ecology & & 602 \\
\hline & $\square$ & landscape ecology & & 4586 \\
\hline & $\square$ & marine ecology & & 949 \\
\hline & 回 & micrnhial ecolngy & & 2890 \\
\hline & $\square$ & palaeoecology & & 3505 \\
\hline & $\square$ & phenology & & 13073 \\
\hline & $\square$ & plant ecology & & 7454 \\
\hline & $\square$ & population ecology & & 3293 \\
\hline & $\square$ & restoration ecology & & 1668 \\
\hline & $\square$ & riparian ecology & & 56 \\
\hline & 口 & synecology & & 4362 \\
\hline & \multicolumn{4}{|c|}{ [Related Terms] } \\
\hline & $\square$ & biocoenosis & & 344 \\
\hline & $\square$ & biodiversity & & 36118 \\
\hline & $\square$ & bioenergetics & & 536 \\
\hline & 田 & biogeography & & 3304 \\
\hline & 四 & ecological balance & & 465 \\
\hline & $\square$ & ecological disturbance & & 5000 \\
\hline & $\square$ & ecologists & & 12 \\
\hline & 四 & ecosystems & & 25391 \\
\hline & $\square$ & ecotypes & & 3275 \\
\hline & $\square$ & environmental degradation & & 8427 \\
\hline & $\square$ & environmental factors & & 31508 \\
\hline & $\square$ & food chains & & 1293 \\
\hline & $\square$ & food webs & & 2264 \\
\hline & $\square$ & habitats & & 43231 \\
\hline & $\square$ & landscape & & 15144 \\
\hline & $\square$ & lowland areas & & 1719 \\
\hline & $\square$ & microenvironments & & 228 \\
\hline & $\square$ & plant communities & & 21514 \\
\hline & $\square$ & populations & & 6551 \\
\hline & $\square$ & predator prey relationships & & 2929 \\
\hline & $\square$ & species diversity & & 37244 \\
\hline & 回 & species richness & & 31934 \\
\hline
\end{tabular}

Figure 1 Narrower terms and 22 related terms of ecology. 
We selected terms with more than 200 hits and used Microsoft Excel to rank them in descending order. We then removed the words "ecology" and "forest" from the Excel sheet and added the terms "climate," "soils," "physiography," "carbon balance" and "nutrient cycling," based on the concepts related to forest ecology defined by Barnes et al. (1997). Then, we defined the remaining 43 search terms and constructed a new search query. The search was limited to "article" type publications published between 1 January 2002 and 31 December 2011 in English.

The search query included 43 terms (see Appendix A). This query was run in Web of Science, which is a citation database of the Web of Knowledge, and a total of 78,986 forest ecology-related articles were identified.

Using the Web of Science's analysis tools, we exported the 78,986 articles by country/region, organization, funding agency, research area, author, year, and publication. The statistical methods used by the Web of Science for the above statistical indicators of multi-author articles do not distinguish between the order of author's locations, which may result the sum of these statistical result was greater than 78,986. The article records, including title, author, keywords, abstract, and organization, were exported in full record mode from the Web of Science to text files. A total of 158 text files were created, because the Web of Science limits each export to 500 records. In every text file, "author keywords" were marked by "DE," and "keywords plus" were provided by the Web of Science and marked by "ID". Both these two kinds of keywords were considered in this study.

\section{Keywords analysis}

First, the frequency of each keyword was counted in each text file. We developed a java program named count.java (Additional file 1: Appendix B) using Eclipse software, a famous cross-platform integrated development environment. This java program can find and select keywords in the output text file by identifying parameters, and connect each keyword to a long string, while deleting the carriage returns. After detection, the keywords in the string were split by semicolons, and counted using HashMap traversal algorithm. The HashMap traversal result was saved to an array and sorted by the counters; then, the sorted result was exported to an intermediate file.

Second, the 158 intermediate files were merged, and the frequency of each keyword was counted. We developed a java program named merge.java (Additional file 1: Appendix C) using Eclipse software. When this program was run, the intermediate files defined in the input parameters were opened, and the keywords and their counters were saved to a HashMap. Then the keywords were counted again with HashMap traversal algorithm: the counters of the same keywords were added. Then, the
HashMap traversal result was saved to an array, sorted by the counters, and exported into a result file.

Third, we developed a program (Additional file 1: Appendix D) to create a java package named frequency. jar to store the compiled java class files which were produced by compiling count.java and merge.java.

Fourth, we developed a batch program named count. bat (Additional file 1: Appendix E) to call the count.class with the input parameters "DE" and "ID". All 158 text files were processed one by one. As a result, 158 intermediate files were created.

Fifth, we developed another batch program named merge.bat (Additional file 1: Appendix F) to call the merge.class with the input parameters, that is, the 158 intermediate files, to merge them. As a result, a final file was created, in which all keywords in 78,986 articles were counted and sorted.

After data processing, 937,923 keywords from those 78,986 articles were merged into 150,974 keywords. All of the keywords were sorted in reverse order based on their frequencies. The 100 most frequently used keywords became the focus of our study.

\section{Results}

\section{Keywords analysis results}

To narrow the research scope, the 100, 200, 300 most frequently used keywords were selected and analyzed. As a result, the 100 most frequently used keywords, $0.07 \%$ of the 150,974 unique keywords analyzed here represented $18.54 \%$ of the total $(937,923)$ of all keywords harvested (Table 1). We focused on the top 100 keywords to examine the hot topics of forest ecology research (Table 2).

\section{Articles analysis result By country/region}

The 78,986 articles were analyzed by countries or regions and sorted in reverse order by their total numbers and Table 3 lists the results for the top 20 countries. We supplemented a column in the original table and classified these 20 countries/regions by their respective continents, which showed that North America and 12 European countries had about $44.71 \%$ and $42.35 \%$ of all the articles, respectively, indicating published articles related to forest ecology in North America and Europe predominate.

Table 1 The top 100, 200, 300 keyword ratio and their frequencies

\begin{tabular}{llll}
\hline $\begin{array}{l}\text { Keywords } \\
\text { number }\end{array}$ & $\begin{array}{l}\text { Keywords } \\
\text { ratio }\end{array}$ & $\begin{array}{l}\text { Keywords } \\
\text { frequencies }\end{array}$ & $\begin{array}{l}\text { Frequencies Ratio } \\
\text { (\%) }\end{array}$ \\
\hline 100 & $0.07 \%(100 / 150974)$ & 173925 & $18.54 \%(173925 / 937923)$ \\
200 & $0.13 \%(200 / 150974)$ & 233042 & $24.85 \%(233042 / 937923)$ \\
300 & $0.20 \%(300 / 150974)$ & 271233 & $28.92 \%(271233 / 937923)$ \\
\hline
\end{tabular}


Table 2 The top 100 keywords in forest ecology articles indexed using the Web of Science during 2002-2011

\begin{tabular}{lll}
\hline & Keywords & Frequencies \\
\hline 1 & forest & 9302
\end{tabular}

diversity

conservation

dynamics

vegetation

biodiversity

patterns

growth

rain-forest

management

nitrogen

forests

soil

ecology

communities

carbon

climate-change

ecosystems

disturbance

species richness

boreal forest

landscape

biomass

model

climate

fire

abundance

united-states

habitat

temperature

plants

organic-matter

populations

decomposition

climate change

dispersal

responses

regeneration

tropical forest

land-use

habitat fragmentation

trees

fragmentation
5424

5135

4886

4720

4613

4166

4069

3253

3236

3136

3069

2793

2677

2596

2568

2412

2407

2389

2381

2334

2180

2130

2100

2095

2043

1855

1849

1846

1824

1782

1755

1733

1603

1599

1590

1576

1531

1513

1509

1495

1486

1473
Table 2 The top 100 keywords in forest ecology articles indexed using the Web of Science during 2002-2011 (Continued)

\begin{tabular}{|c|c|c|}
\hline 44 & forest soils & 1441 \\
\hline 45 & evolution & 1408 \\
\hline 46 & succession & 1384 \\
\hline 47 & deforestation & 1375 \\
\hline 48 & ecosystem & 1362 \\
\hline 49 & birds & 1333 \\
\hline 50 & population & 1276 \\
\hline 51 & competition & 1273 \\
\hline 52 & water & 1235 \\
\hline 53 & variability & 1210 \\
\hline 54 & deciduous forest & 1190 \\
\hline 55 & forest management & 1189 \\
\hline 56 & community structure & 1178 \\
\hline 57 & behavior & 1140 \\
\hline 58 & community & 1131 \\
\hline 59 & restoration & 1127 \\
\hline 60 & tropical forests & 1107 \\
\hline 61 & photosynthesis & 1093 \\
\hline 62 & seed dispersal & 1081 \\
\hline 63 & usa & 1067 \\
\hline 64 & productivity & 1054 \\
\hline 65 & microbial biomass & 1040 \\
\hline 66 & density & 1034 \\
\hline 67 & impact & 1019 \\
\hline 68 & brazil & 1018 \\
\hline 69 & models & 988 \\
\hline 70 & carbon-dioxide & 978 \\
\hline 71 & phosphorus & 971 \\
\hline 72 & size & 971 \\
\hline 73 & predation & 947 \\
\hline 74 & classification & 943 \\
\hline 75 & respiration & 932 \\
\hline 76 & scale & 927 \\
\hline 77 & drought & 920 \\
\hline 78 & national-park & 918 \\
\hline 79 & plant & 910 \\
\hline 80 & selection & 909 \\
\hline 81 & tree & 902 \\
\hline 82 & deposition & 889 \\
\hline 83 & history & 888 \\
\hline 84 & recruitment & 875 \\
\hline 85 & norway spruce & 874 \\
\hline 86 & soil respiration & 870 \\
\hline
\end{tabular}


Table 2 The top 100 keywords in forest ecology articles indexed using the Web of Science during 2002-2011 (Continued)

\begin{tabular}{lll}
\hline 87 & australia & 868 \\
88 & consequences & 864 \\
89 & tropical rain-forest & 839 \\
90 & survival & 834 \\
91 & quality & 830 \\
92 & mexico & 819 \\
93 & costa-rica & 813 \\
94 & impacts & 812 \\
95 & new-zealand & 796 \\
96 & forest soil & 794 \\
97 & mortality & 788 \\
98 & soils & 787 \\
99 & grassland & 786 \\
100 & assemblages & 785 \\
\hline
\end{tabular}

The combined frequency of keywords related to tropical forest, represented by "rain-forest" $(3,253)$, "tropical forest" $(1,513)$, "tropical forests" $(1,107)$, and "tropical rain-forest" (839), totaled 6,712 keyword entries, which was exceeded only by the keyword "forest" with 9,302 entries (Table 2). This indicates that tropical forest was the main focus of

Table 3 Top 20 countries/regions publishing articles on forest ecology indexed using the web of science during 2002-2011

\begin{tabular}{|c|c|c|c|c|}
\hline & Countries/Regions & Records & Ratio (\%) & Continents \\
\hline 1 & USA & 28060 & 35.53 & North America \\
\hline 2 & Canada & 7255 & 9.19 & North America \\
\hline 3 & Germany & 6311 & 7.99 & Europe \\
\hline 4 & Brazil & 4561 & 5.77 & Africa \\
\hline 5 & Australia & 4375 & 5.54 & Australia \\
\hline 6 & England & 4229 & 5.35 & Europe \\
\hline 7 & Peoples R China & 4122 & 5.22 & Asia \\
\hline 8 & France & 3930 & 4.98 & Europe \\
\hline 9 & Japan & 3504 & 4.44 & Asia \\
\hline 10 & Spain & 3402 & 4.31 & Europe \\
\hline 11 & Sweden & 2708 & 3.43 & Europe \\
\hline 12 & Finland & 2417 & 3.06 & Europe \\
\hline 13 & Italy & 2230 & 2.82 & Europe \\
\hline 14 & Netherlands & 1921 & 2.43 & Europe \\
\hline 15 & Switzerland & 1871 & 2.37 & Europe \\
\hline 16 & India & 1798 & 2.28 & Asia \\
\hline 17 & Mexico & 1572 & 1.99 & South America \\
\hline 18 & Russia & 1554 & 1.97 & Europe \\
\hline 19 & Scotland & 1455 & 1.84 & Europe \\
\hline 20 & New Zealand & 1421 & 1.80 & Europe \\
\hline
\end{tabular}

Table 4 Top 20 organizations publishing articles on forest ecology indexed using the web of science during 2002-2011

\begin{tabular}{cllcl}
\hline & Organizations & Records & Ratio (\%) & Counties \\
\hline 1 & Univ Calif System & 2749 & 3.48 & USA \\
2 & Chinese Acad SCI & 2359 & 2.99 & China \\
3 & US Forest Serv & 2203 & 2.79 & USA \\
4 & Swedish Univ Agr SCI & 1342 & 1.70 & Sweden \\
5 & Oregon State Univ & 1200 & 1.52 & USA \\
6 & Univ Helsinki & 1055 & 1.34 & Finland \\
7 & Univ British Columbia & 1008 & 1.28 & Canada \\
8 & Univ Wisconsin System & 978 & 1.24 & USA \\
9 & Univ Alberta & 973 & 1.23 & Canada \\
10 & Russian Acad SCl & 925 & 1.17 & Russia \\
11 & Univ Florida & 905 & 1.15 & USA \\
12 & USDA & 905 & 1.15 & USA \\
13 & Univ Sao Paulo & 896 & 1.13 & Brazil \\
14 & US Geol Survey & 883 & 1.12 & USA \\
15 & Univ Fed Santa Maria & 868 & 1.10 & Brazil \\
16 & Smithsonian Inst & 867 & 1.10 & USA \\
17 & Max Planck Society & 808 & 1.02 & Germany \\
18 & Univ Gottingen & 785 & 0.99 & Germany \\
19 & INRA & 771 & 0.98 & France \\
20 & CSIC & 766 & 0.97 & Spain \\
\hline USDA Unit & & &
\end{tabular}

USDA United States department of agriculture, INRA Institut National de la recherche agronomique, CSIC consejo superior de investigaciones científicas.

research in forest ecology studies. Tropical forest is mainly distributed in Southeast Asia, Central America, South America, Australia, Africa. However, the main countries with strong research capabilities related to tropical forest research were not located in those areas, but were found in North America and Europe.

\section{By organization}

Forest ecology studies were conducted by 7,598 organizations, and Table 4 lists the top 20 organizations and their related countries. The University of California System, the Chinese Academy of science, and US Forest Service produced the most articles. Eight organizations were from the USA, two each from Canada, Brazil, and Germany, and the remaining six were from China, Sweden, Finland, Russia, Spain, and France.

\section{By funding agency}

6,356 funding agencies subsidized forest ecology studies, and the top 20 were exported for closer analysis. Because many articles used abbreviations for the funding agencies the top 20 were merged into 15 (Table 5). Examples include the National Science Foundation (NSF), the Conselho Nacional de Desenvolvimento Científico e Tecnológico 
Table 5 The 15 most productive agencies funding forest ecology research indexed by the web of science during 2002-2011

\begin{tabular}{lllll}
\hline Funding agencies & $\begin{array}{c}\text { Articles } \\
\text { number }\end{array}$ & $\begin{array}{c}\text { Ratio } \\
\text { (\%) }\end{array}$ & Countries \\
\hline 1 & National Science Foundation & 2240 & 2.84 & USA \\
2 & National Natural Science Foundation & 831 & 1.05 & China \\
& of China & & & \\
3 & Natural Sciences and Engineering & 807 & 1.02 & Canada \\
& Research Council of Canada & & & \\
4 & CNPq & 744 & 0.94 & Brazil \\
5 & European Union & 601 & 0.76 & EU \\
6 & Chinese Academy of Sciences & 372 & 0.47 & China \\
7 & NASA & 357 & 0.45 & USA \\
8 & European Commission & 337 & 0.43 & EC \\
9 & Academy of Finland & 311 & 0.39 & Finland \\
10 & Australian Research Council & 265 & 0.34 & Australia \\
11 & CAPES & 221 & 0.28 & Brazil \\
12 & National Basic Research Program of China & 196 & 0.25 & China \\
13 & FAPESP & 192 & 0.24 & Brazil \\
14 & Russian Foundation for Basic Research & 185 & 0.23 & Russia \\
15 & USDA Forest Service & 172 & 0.22 & USA \\
\hline
\end{tabular}

CNPQ: Conselho Nacional de Desenvolvimento Científico e Tecnológico, Brazil; NASA: National Aeronautics and Space Administration, USA; CAPES: Coordenação de Aperfeiçoamento de Pessoal de Nivel Superior, Brazil; FAPESP: Fundação de Amparo à Pesquisa do Estado de São Paulo, Brazil; EC: European Commission.

Table 6 The top 20 research areas related to forest ecology indexed using the web of science during 2002-2011

\begin{tabular}{llll}
\hline & Research areas & $\begin{array}{l}\text { Articles } \\
\text { number }\end{array}$ & $\begin{array}{l}\text { Ratio } \\
\text { (\%) }\end{array}$ \\
\hline 1 & Environmental Sciences Ecology & 31172 & 39.47 \\
2 & Forestry & 13164 & 16.67 \\
3 & Agriculture & 8354 & 10.58 \\
4 & Plant Sciences & 8027 & 10.16 \\
5 & Zoology & 6470 & 8.19 \\
6 & Biodiversity Conservation & 6005 & 7.60 \\
7 & Geology & 5660 & 7.17 \\
8 & Meteorology Atmospheric Sciences & 3654 & 4.63 \\
9 & Physical Geography & 3453 & 4.37 \\
10 & Water Resources & 2521 & 3.19 \\
11 & Marine Freshwater Biology & 2271 & 2.88 \\
12 & Entomology & 2176 & 2.76 \\
13 & Engineering & 1981 & 2.51 \\
14 & Life Sciences Biomedicine Other Topics & 1650 & 2.09 \\
15 & Evolutionary Biology & 1631 & 2.07 \\
16 & Remote Sensing & 1611 & 2.04 \\
17 & Science Technology Other Topics & 1319 & 1.67 \\
18 & Biochemistry Molecular Biology & 1269 & 1.61 \\
19 & Imaging Science Photographic Technology & 1205 & 1.53 \\
20 & Genetics Heredity & 1079 & 1.37 \\
\hline
\end{tabular}

Table 7 The $\mathbf{2 0}$ most productive authors of research papers related to forest ecology indexed using the Web of Science during 2002-2011

\begin{tabular}{lllll}
\hline & Authors & Authors' countries & Articles number & Ratio (\%) \\
\hline 1 & Bergeron Y & Canada & 146 & 0.19 \\
2 & Kulmala M & Finland & 123 & 0.16 \\
3 & Hermy M & Belgium & 114 & 0.14 \\
4 & Lindenmayer DB & Australia & 110 & 0.14 \\
5 & Black TA & Canada & 103 & 0.13 \\
6 & Coops NC & Canada & 95 & 0.12 \\
7 & Asner GP & USA & 91 & 0.12 \\
8 & Verheyen K & Belgium & 91 & 0.12 \\
9 & Reich PB & USA & 87 & 0.11 \\
10 & Penuelas J & Spain & 85 & 0.11 \\
11 & Vesala T & Finland & 85 & 0.11 \\
12 & Leuschner C & Germany & 81 & 0.10 \\
13 & Peres CA & England & 81 & 0.10 \\
14 & Chen JM & Canada & 80 & 0.10 \\
15 & Ciais P & France & 80 & 0.10 \\
16 & Groffman PM & USA & 79 & 0.10 \\
17 & Law BE & USA & 78 & 0.10 \\
18 & Malhi Y & England & 78 & 0.10 \\
19 & Fahey TJ & USA & 77 & 0.10 \\
20 & Yu GR & China & 77 & 0.10 \\
\hline
\end{tabular}

(CNPq), the European Union (EU), and the Natural Sciences and Engineering Research Council of Canada (NSERC).

The National Science Foundation (USA), National Natural Science Foundation of China (China), Natural Sciences and Engineering Research Council of Canada (Canada), Conselho Nacional de Desenvolvimento Científico e Tecnológico (Brazil), and European Commission were more prolific in forest ecology than other funding agencies. Combining the number of articles in Table 5 by country/ region demonstrates that the USA $(2,769)$, China $(1,399)$,

Table 8 Annual number of articles on forest ecology indexed using the Web of Science during 2002-2011

\begin{tabular}{llll}
\hline & Years & Articles number & Ratio (\%) \\
\hline 1 & 2002 & 5245 & 6.64 \\
2 & 2003 & 5729 & 7.25 \\
3 & 2004 & 6250 & 7.91 \\
4 & 2005 & 6816 & 8.63 \\
5 & 2006 & 7555 & 9.57 \\
6 & 2007 & 8098 & 10.25 \\
7 & 2008 & 8970 & 11.36 \\
8 & 2009 & 9311 & 11.79 \\
9 & 2010 & 10096 & 12.78 \\
10 & 2011 & 10915 & 13.82 \\
\hline
\end{tabular}




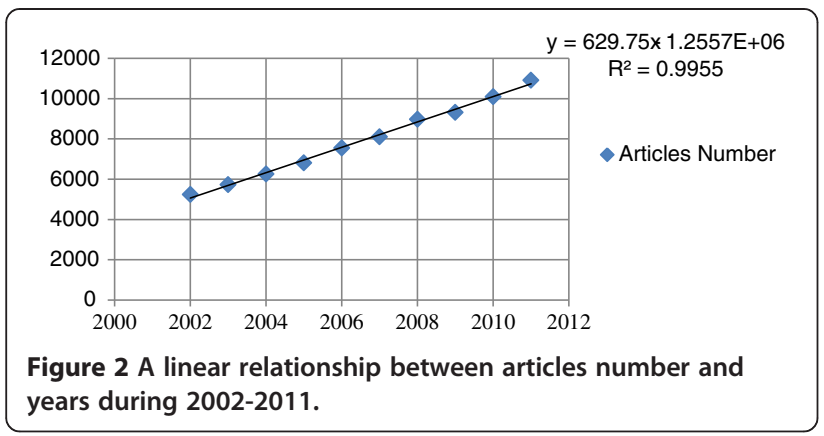

Brazil $(1,157)$, Canada (807), and EU (601) were also the top five countries/regions and provided more financial aid to forest ecology research than other countries.

\section{By research area}

In the analysis, forest ecology was related to 72 research areas identified by the Web of Science data. Table 6 lists the top 20 research areas and clearly shows that forest ecology studies were related to a wide range of disciplines. Environmental sciences ecology (31,172 or $39.47 \%$ of all articles), forestry $(13,164,16.67 \%)$, agriculture $(8,354,10.58 \%)$, and plant sciences $(8,027,10.16 \%)$ were the top four major related research areas.

Table 9 The top 20 journals related to forest ecology analyzed using the Web of Science during 2002-2011

\begin{tabular}{llll}
\hline & Publications & $\begin{array}{l}\text { Articles } \\
\text { number }\end{array}$ & $\begin{array}{l}\text { Ratio } \\
\text { (\%) }\end{array}$ \\
\hline 1 & Forest Ecology and Management & 3876 & 4.91 \\
2 & Canadian Journal of Forest Research & 1399 & 1.77 \\
3 & Biological Conservation & 933 & 1.18 \\
4 & Soil Biology Biochemistry & 929 & 1.18 \\
5 & Biodiversity and Conservation & 928 & 1.18 \\
6 & Global Change Biology & 824 & 1.04 \\
7 & Ecology & 750 & 0.95 \\
8 & Oecologia & 741 & 0.94 \\
9 & Biotropica & 666 & 0.84 \\
10 & Plant and Soil & 653 & 0.83 \\
11 & Ecological Applications & 636 & 0.81 \\
12 & Plant Ecology & 614 & 0.78 \\
13 & Ecological Modeling & 523 & 0.76 \\
14 & Remote Sensing of Environment & 598 & 0.76 \\
15 & Argicultural and Forest Meteorology & 589 & 0.69 \\
16 & Journal of Tropical Ecology & 543 & 0.65 \\
17 & Journal of Geophysical Research & 516 & \\
\hline 19 & Jtmospheres & 508 & 0.65 \\
\hline
\end{tabular}

\section{By author}

A total of 48,373 authors participated in forest ecology related studies. Among the 20 authors publishing the most articles, five were from the USA, four were from Canada, and two each were from Belgium, Finland, and England (Table 7).

\section{By year}

From 2002 to 2011, the annual number of published articles about forest ecology was growing at a stable rate (Table 8), as the fit produced a high determination coefficient from the collected data $\left(R^{2}=0.9955\right)$. The best fit for forest ecology was found to be: $y=629.75 x$ $1.2557 \exp +06$, where $y$ is the article number and $x$ is the number of years since 2002. Extrapolating from the model, the number of articles about forest ecology in the following years could be forecasted (Figure 2).

\section{By publication}

The number of journals publishing forest ecology related articles each year increased from 430 in 2002 to 856 in 2011. Table 9 shows the top 20 major journals indicating that Forest Ecology and Management (3,876, 4.91\%) was the top journal on forest ecology by article count, followed by Canadian Journal of Forest Research (1,399, $1.77 \%)$ and Biological Conservation (1,399, 1.77\%).

\section{Discussion}

The results of this study pointed to several significant hotspots in global research related to forest ecology based on an analysis of article keywords for articles published during 2002-2011, and revealed the distribution of the articles from seven aspects listed above. The keyword analysis method and the java analysis program could be extended to other related research fields.

In the keywords analysis, we presumed that a keyword appeared only once in the keywords list of an article (Campbell 1963). Therefore the frequency of a keyword could show the number of articles that had used this keyword. For example, the frequency of "forest" was 9,302, meaning that 9,302 articles had used "forest" as a keyword in 73,740 articles.

It was undisputed that "forest" was the most frequently used keyword (9,302 articles). Most writers used this word to express the concept of "forest" instead of its plural "forests"; therefore, "forest" appeared in articles three times more than "forests" $(3,069)$. The next four most frequently used words were "diversity" $(5,424)$, "conservation" $(5,135)$, "dynamics" $(4,886)$, and "vegetation" $(4,720)$ indicating forest diversity, forest conservation, forest dynamics and forest vegetation were the focus of forest ecological studies.

The frequency of "patterns" $(4,166)$, "model" $(2,100)$, and "models" (988) demonstrated that these words were 
widely used in forest developmental pattern and model studies. The keywords "management" $(3,236)$, "ecology" $(2,677)$, "ecosystems" $(2,407)$, and "ecosystem" $(1,362)$ were also frequently used in macro research $(9,682$ times), accounting for $1.03 \%$ in all keywords indicating large numbers of studies had been carried out in these aspects of forest research in last ten years.

USA" (2,916), "Brazil" (1,018), "Australia" (868), "Mexico" (819), "Costa Rica" (813) and "New Zealand" (796) appeared more frequently than the names of other countries showing that many studies focused on those countries. During the early twenty-first century, the warm droughts in the United States, Europe and Australia have been recognized as a considerable change from the climatological conditions and variability of the late twentieth century (Dai 2011), and the focus of forest ecology studies in those regions were impacted accordingly. From a regional point of view, we can see that the total frequencies of "rain-forest" $(3,253)$, "tropical forests" $(1,107)$, and "tropical forest" $(1,513)$ were 5,873, 2.5 times more frequent than "boreal forest" $(2,334)$, indicating that forest ecology studies concerning tropical forests were produced more frequently than those related to boreal forests.

In 2005, large-scale, warm droughts occurred in North America, Africa, Europe, Amazonia and Australia, resulting in major effects on terrestrial ecosystems, carbon balance and food security (Breshears 2005). The words "nitrogen" $(3,136)$, "carbon" $(2,568)$, and "phosphorus" (971) were used frequently in the studies concerning elemental nutrients. There were numerous studies related to how the climate is affecting forest ecology, as indicated by the frequencies of "climate-change", "climate", and "climate change," which were 2,412, 2,095 and 1,599, respectively.

This study did reveal some problem areas. Some keywords were not being used consistently, such as soil, soils, forest soil and forest soils, which all pointed to the same thing: forest soil. Another example was that tropical forest and tropical forests also expressed similar meanings. The use of multiple keywords for a single concept might be related to the writing styles and habits of different authors, but this creates difficulty in statistical analysis.

The USA, Canada, and Germany were the top three most productive countries of forest ecology related research. The most three productive organizations were the University of California System, Chinese Academy of Sciences, and the US Forest Service. The three most productive funding agencies were the National Science Foundation, the National Natural Science Foundation of China, and the Natural Sciences and Engineering Research Council of Canada. Environmental science / ecology, forestry, and agriculture were the top three most popular categories. The spatial clusters of authors were mainly in the USA and Canada. Forest Ecology and
Management, Canadian Journal of Forest Research, and Biological Conservation were the top three journals with the most publications related to forest ecology research. In the article analysis, the results by country/region, organization, funding agency, author distribution, and sources titles, was clustered in developed countries, apparently because these countries have economic strength required to invest in science and technology.

In this study, the limitations of search term expressions and the English language made it impossible to include all related keywords in the field of forest ecology research, especially in other languages. This study did not analyze the effects of cooperation between authors and joint papers by authors from multiple nations. In the journal sort, the impact factor of the journal was not considered.

\section{Conclusions}

A serial java program was developed and applied to conduct keyword frequency analysis. That improved the efficiency of data processing and provided an analysis method. Keyword analysis offered insight into forest ecology research areas of interest, while the abundance of less frequent keywords suggested a lack of continuity in research and a wide disparity in the focus of forest ecology research. The top 100 keywords in the keyword analysis were almost all included in the top 20 research areas in the article analysis, so one could conclude that keyword frequency analysis is consistent with article research area analysis. Their difference is the former is concrete and the latter is abstract.

\section{Appendix A}

( $\mathrm{TS}=$ (habitats) or $\mathrm{TS}=$ (species diversity) or $\mathrm{TS}=$ (biodiversity) or TS $=$ (species richness) or TS $=($ environmental factors) or TS $=$ (ecosystems) or $\mathrm{TS}=$ (plant communities) or $\mathrm{TS}=$ (landscape) or $\mathrm{TS}=$ (phenology) or TS = (environmental degradation) or $\mathrm{TS}=($ plant $)$ or $\mathrm{TS}=$ (populations $)$ or $\mathrm{TS}=($ animal $)$ or $\mathrm{TS}=$ (ecological disturbance) or $\mathrm{TS}=$ (landscape) or $\mathrm{TS}=$ (synecology) or TS $=$ (palaeo ecology) or TS $=$ (community) or $\mathrm{TS}=$ (biogeography) or $\mathrm{TS}=$ (population) or $\mathrm{TS}=$ (ecotypes) or $\mathrm{TS}=$ (predator prey relationships) or TS $=($ microbial $)$ or $\mathrm{TS}=($ fresh water) or TS $=$ (food webs) or TS $=$ (lowland areas) or $\mathrm{TS}=($ restoration $)$ or $\mathrm{TS}=($ fire $)$ or $\mathrm{TS}=($ food chains $)$ or $\mathrm{TS}=$ (autecology) or $\mathrm{TS}=$ (marine) or $\mathrm{TS}=$ (chemical) or TS $=$ (human) or TS $=$ (bioenergetics) or $\mathrm{TS}=$ (ecological balance) or $\mathrm{TS}=$ (bio coenosis $)$ or $\mathrm{TS}=$ (microenvironments) or $\mathrm{TS}=$ (dendro ecology) or $\mathrm{TS}=$ (climate) or $\mathrm{TS}=($ soils $)$ or $\mathrm{TS}=$ (physiography) or $\mathrm{TS}=$ (carbon balance) or $\mathrm{TS}=$ (nutrient cycling) and (TS = (forest). 


\section{Additional file}

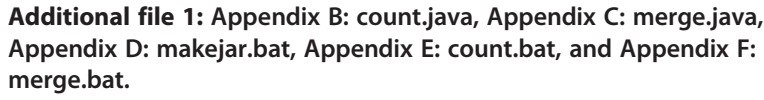

\section{Competing interests}

The authors declare that they have no competing interests.

\section{Authors' contributions}

YS carried out the bibliometric analysis, and drafted the manuscript. TZ gave financial assistance and some advice to this manuscript. Both authors read and approved the final manuscript.

\section{Acknowledgements}

This study was supported by the Forestry Commonweal Programs (No. 200904003) from State Forestry Administration, P.R.China. The authors greatly appreciate the technical support of Peng Shi, Yingni Zou, and Ying Pan. The authors are grateful to Yungang Liao for his helpful suggestions. The authors would also like to thank the chief editor of SpringerPlus and anonymous reviewers for their valuable comments.

\section{Author details}

'School of Information Science \& Technology, Beijing Forestry University, No.35 Tsinghua East Road, Beijing, Haidian District 100083, P.R. China. ${ }^{2}$ Library of Beijing International Studies University, No.1 Dingfuzhuang Nanli, Beijing, Chaoyang District 100024, P.R. China.

Received: 4 February 2013 Accepted: 16 April 2013

Published: 2 May 2013

\section{References}

Barnes BV, Zak DR, Denton SR, Spurr SH (1997) Forest ecology. http://www cabdirect.org/abstracts/19980607188.html

Berger TW, Inselsbacher E, Mutsch F, Pfeffer M (2009) Nutrient cycling and soil leaching in eighteen pure and mixed stands of beech (Fagus sylvatica) and spruce (Picea abies). Forest Ecol Manag 258(11):2578-2592

Breshears DD (2005) Regional vegetation die-off in response to global-change-type drought. Proc Natl Acad Sci 102:15144-15148

Campbell DJ (1963) Making your own indexing system in science and technology (classification and keyword systems). ASLIB Proc 15(10)

Cheaib A, Badeau V, Boe J, Chuine I, Delire C, Dufrêne E et al (2012) Climate change impacts on tree ranges: model intercomparison facilitates understanding and quantification of uncertainty. Ecol Lett 15(6):533-544

Dai A (2011) Drought under global warming: a review. WIRES Climate Change (2):45-65

Diaz S, Lavorel S, de Bello F, Quetier F, Grigulis K, Robson M (2007) Incorporating plant functional diversity effects in ecosystem service assessments. Proc Natl Acad Sci USA 104(52):20684-20689

Dobbertin M, Nobis M (2010) Exploring research issues in selected forest journals 1979-2008. Ann Forest Sci 67(8):800

Grandjean P, Eriksen M, Ellegaard O, Wallin J (2011) The Matthew effect in environmental science publication: A bibliometric analysis of chemical substances in journal articles. Environ Health 10(1):1

Hanberry BB, Kabrick JM, He HS, Palik BJ (2012) Historical trajectories and restoration strategies for the Mississippi River Alluvial Valley. Forest Ecol Manag 280:103-111. doi:10.1016

Hendrix D (2008) An analysis of bibliometric indicators, National Institutes of Health funding, and faculty size at Association of American Medical Colleges medical schools, 1997-2007. J Med Libr Assoc 96(4):324-334

Lamb D, Erskine P, Parrotta J (2005) Restoration of degraded tropical forest landscapes. Science 310(5754):1628-1632

Loucks CJ, Lu Z, Dinerstein E, Wang H, Olson DM, Zhu C et al (2001) Ecology. Giant pandas in a changing landscape. Science 294(5546):1465

McLachlan SM, Bazely DR (2003) Outcomes of longterm deciduous forest restoration in southwestern Ontario, Canada. Biol Conserv 113(2):159-169

Mitchell SR, Harmon ME, O'Connell KEB (2009) Forest fuel reduction alters fire severity and long-term carbon storage in three Pacific Northwest ecosystems. Ecol Appl 19(3):643-655
Morrissey RC, Gauthier M, Kershaw JA Jr, Jacobs DF, Seifert JR, Fischer BC (2009) Grapevine (Vitis spp.) dynamics in association with manual tending physiography, and host tree associations in temperate deciduous forests. Forest Ecol Manag 257(8):1839-1846

Narotsky D, Green PH, Lebwohl B (2012) Temporal and geographic trends in celiac disease publications: a bibliometric analysis. Eur J Gastroenterol Hepatol 24(9):1071-1077

Perez M, Fu M, Xie J, Yang X, Belcher B (2004) The relationship between forest research and forest management in China: an analysis of four leading Chinese forestry journals. Int For Rev 6(3-4):341-345

Rodrigues RR, Gandolfi S, Nave AG, Aronson J, Barreto TE, Vidal CY et al (2011) Large-scale ecological restoration of high-diversity tropical forests in SE Brazil. Forest Ecology Manag 261(10):1605-1613

Rubio A, Escudero A (2005) Effect of climate and physiography on occurrence and intensity of decarbonation in Mediterranean forest soils of Spain Geoderma 125(3-4):309-319

Sekercioğlu ÇH, Primack RB, Wormworth J (2012) The effects of climate change on tropical birds. Biol Conserv 148(1):1-18

Sillett SC, Van Pelt R, Koch GW, Ambrose AR, Carroll AL, Antoine ME et al (2010) Increasing wood production through old age in tall trees. Forest Ecol Manag 259(5):976-994

Sitzia T, Semenzato P, Trentanovi G (2010) Natural reforestation is changing spatial patterns of rural mountain and hill landscapes: A global overview. Forest Ecol Manag 259(8):1354-1362

van Eck NJ, Waltman L, Dekker R, van den Berg J (2010) A comparison of two techniques for bibliometric mapping: Multidimensional scaling and VOS. J Am Soc Inf Sci Technol 61(12):2405-2416

van Oudenhoven APE, Petz K, Alkemade R, Hein L, de Groot RS (2012) Framework for systematic indicator selection to assess effects of land management on ecosystem services. Ecol Indic 21:110-122

van Raan AFJ (2006) Comparison of the Hirsch-index with standard bibliometric indicators and with peer judgment for 147 chemistry research groups. Scientometrics 67(3):491

Wang Q, Wang S, Yu X (2011) Decline of soil fertility during forest conversion of secondary forest to Chinese fir plantations in substropical China. Land Degradation Dev 22(4):444-452

Wintle B, Bekessy S, Venier L, Pearce J, Chisholm R (2005) Utility of dynamic-landscape metapopulation models for sustainable forest management. Conserv Biol 19 (6):1930-1943

Xu Z, Chen C (2006) Fingerprinting global climate change and forest management within rhizosphere carbon and nutrient cycling processes. Environ Sci Pollut Res 13(5):293

doi:10.1186/2193-1801-2-204

Cite this article as: Song and Zhao: A bibliometric analysis of global forest ecology research during 2002-2011. SpringerPlus 2013 2:204.

\section{Submit your manuscript to a SpringerOpen ${ }^{\circ}$ journal and benefit from:}

- Convenient online submission

- Rigorous peer review

- Immediate publication on acceptance

- Open access: articles freely available online

- High visibility within the field

- Retaining the copyright to your article

Submit your next manuscript at $>$ springeropen.com 